Häusliche Mundhygiene bei Gingivitis und Parodontitis - Teil 3

\title{
Zahnbürsten im wissenschaftlichen
} Vergleich

Gingivitis- und Parodontitispatienten benötigen eine problemorientierte Lösung, die dem gereizten und entzündeten Zahnfleisch Rechnung trägt, aber auch die täglichen Mundhygienegewohnheiten berücksichtigt und fördert - mit anderen Worten: eine Kombination, die aus Zahnpasta, Zahnbürste und Mundspüllösung (z.B. mit Aminfluorid/Zinnfluorid) besteht, die sich optimal ergänzen. Sind die Produktleistungen durch wissenschaftliche Studien belegt, können Zahnärzte und Verwender sicher sein, eine gute Wahl getroffen zu haben.

D ie besondere Reinigungsleistung der meridol ${ }^{\circledR}$-Zahnbürste am Zahnfleischsaum wurde von der Arbeitsgruppe um Yankell von der School of Dental Medicine der University of Pennsylvania in einer In-vitro-Untersuchung getestet. Hierfür wurden Zahnmodelle von Molaren mit künstlichem Zahnfleisch aus Acrylharz verwendet. Zwischen Zähne und Zahnfleisch wurde druckempfindliches Papier als künstliche Plaque eingeschoben. Dann wurden die Modelle mit Hilfe einer mechanischen Bürstvorrichtung jeweils 4-mal mit der meridol ${ }^{\circledR}$ Zahnbürste und einer international anerkannten Referenzzahnbürste der American Dental Association
(ADA) $60 \mathrm{~s}$ lang horizontal geputzt. Schließlich wurde anhand des druckempfindlichen Papiers gemessen, wie viel künstliche Plaque am Zahnfleischsaum entfernt wurde. Die meridol ${ }^{\circledR}$-Zahnbürste entfernte am Zahnfleischsaum 10,61 mm künstliche Plaque, die Vergleichszahnbürste nur 0,22 mm. Diese Studie zeigt, dass die meridol ${ }^{\circledR}$-Zahnbürste mit ihren mikrofeinen Borstenenden den Zahnfleischsaum deutlich besser reinigt als die Referenzzahnbürste mit ihren zylindrischen, endgerundeten Borsten (Yankell et al. 2003). Auch Sgan-Cohen \& Vered (2005) sehen in der Verwendung der meridol ${ }^{\circledR}$-Zahnbürste Potenzial zum Schutz der Gesundheit der Gingiva.

Die meridol ${ }^{\circledR}$-Zahnbürste kann eine Gingivitis reduzieren und verletzt das Zahnfleisch deutlich weniger als eine Standardzahnbürste. Dies ist das Ergebnis einer klinischen Einfachblindstudie an der Universität Heidelberg. In ihrer Untersuchung verglichen die Wissenschaftler das Verletzungspotenzial der meridol ${ }^{\circledR}$-Zahnbürste mit dem der ADAReferenzzahnbürste. 86 Probanden wurden in 2 Gruppen aufgeteilt und putzten sich 3 Monate lang 2-mal täglich die Zähne mit der meridol ${ }^{\circledR}$ Zahnbürste bzw. der Vergleichszahnbürste. Die Zahnbürsten wurden im Abstand von 6 Wochen jeweils durch

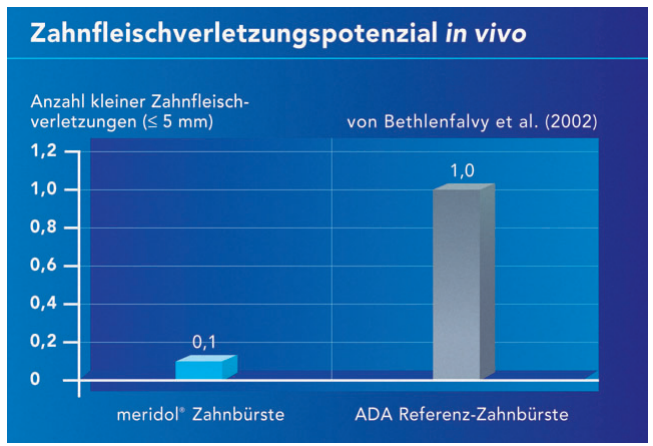

eine neue ausgetauscht. Nach Ablauf der 3 Monate betrug die relative Gingivitisreduktion bei Anwendung der meridol ${ }^{\circledR}$-Zahnbürste $26,8 \%$, während mit der Vergleichszahnbürste eine Reduktion um 23,1\% erzielt wurde. Beide Zahnbürsten können also Zahnfleischentzündungen deutlich reduzieren. Auffällig aber war, dass die Zahl der beim Putzvorgang aufgetretenen Gingivaläsionen bei Anwendung der meridol ${ }^{\circledR}$-Zahnbürste nur ein Zehntel im Vergleich zur Referenzzahnbürste betrug (siehe Abb.) (von Bethlenfalvy et al. 2002).

\section{Literatur}

1. Lang NP, Attström R, Löe H (Hrsg). Proceedings of the European Workshop on Mechanical Plaque Control. Quintessenz 1998 2. Sgan-Cohen HD, Vered YA. Clinical Trial of the meridol ${ }^{\circledR}$ Toothbrush with Conocal Filaments: Evaluation of Clinical Effectiveness and Subjective Satisfaction. J Clin Dent 2005; 16: 109-113

3. van der Weijden GA, Timmerman MF, Danser MM, van der Velden U. Relationship between the plaque removal efficacy of a manual toothbrush and brushing force. J Clin Periodontol 1998; 5: 413-416

4. von Bethlenfalvy ER, Kugel B, Pioch T, Dörfer CE. Einfluss unterschiedlicher Filamente auf die Gingivitisreduktion zweier Handzahnbürsten. Parodontologie 2002; 13: 286-287

5. Yankell SL, Shi X, Emling RC. Laboratory Evaluations of Two Toothbrushes for Removal of Artificial Plaque Above, Around and Below the Gingival Margin. J Clin Dent 2003; 14: $19-22$

Dieser Beitrag entstand in Zusammenarbeit mit der GABA GmbH, Lörrach. 